\title{
SARTRE: O EXISTENCIALISMO EM TORNO DA MORTE
}

\author{
[SARTRE: EXISTENTIALISM AROUND DEATH]
}

Vanessa Furtado Fontana * Universidade Estadual do Oeste do Paraná, Brasil

\begin{abstract}
Resumo: O tema da morte sempre esteve presente na história da filosofia e também está nos textos existencialistas de Sartre. A principal obra que trata da morte é: "O ser e o nada" de 1943, no qual se concentra esse artigo. Nesta obra a morte é vista como limite para a nadificação. Contudo destaca-se também, a importante concepção do existencialismo ateu na obra "O existencialismo é um humanismo", no qual a morte é apresentada como fim, sem as perceptivas de pós-morte do cristianismo. Ainda tratar-se-á do texto "A náusea", como forma de pensar a morte e sua absurdidade. $\mathrm{O}$ tema do absurdo também é descrito na obra "O ser e o nada", e é a primeira chave de leitura para esse fenômeno do limite da vida, mas que ainda é vida. Um último tema a abordar, e nem por isso menos importante, é o ser-para-outro, a concepção da minha morte encarada pelo outro, e como esse outro reage e fundamenta, em certo sentido, minha própria morte.
\end{abstract}

Palavras Chaves: Morte; nadificação; absurdo; existencialismo

\section{INTRODUÇ̃̃O}

E m toda história da filosofia a morte sempre apareceu como tema dentro de pensamentos mais sensíveis e mesmo de ontologias profundas. A morte é a certeza mais trágica que se tem na vida humana, e o fato de se poder refletir sobre ela é ao mesmo tempo uma dádiva e um desafio. Encarar a morte trás a tona certa melancolia, mas também permite pensar os limites morais e existenciais da vida humana. Dentro da filosofia, buscando a sua história, tem-se vários filósofos que se dedicam ao tema da morte. No período clássico da filosofia grega pode-se destacar o filósofo Platão, e sua

Doutora em Filosofia pela Universidade Federal de Santa Catarina - UFSC (2013). Professora da Universidade Estadual do Oeste do Paraná, UNIOESTE, Brasil. E-mail: fontanessa@yahoo.com.br
ABSTRACT: The theme of death has always been present in the history of philosophy and is also present in Sartre's existentialist texts. The main work that deals with death is: "The being and the nothingness" of 1943, on which this article is concentrated. In this work, death is seen as the limit for nadification. However, the important conception of atheistic existentialism in the work "Existentialism is a humanism" also stands out, in which death is presented as an end, without the postmortem perceptions of Christianity. It will also deal with the text "Nausea", as a way of thinking about death and its absurdity. The theme of the absurd is also described in the work "The being and the nothing", and it is the first key for reading this phenomenon of the limit of life, but which is still life. One last issue to be addressed, and no less important, is being-for-another, the conception of my death faced by the other, and how this other reacts and underlies, in a sense, my own death.

KEYWORDS: Death; nadification; absurd; existentialism 
preocupação com a imortalidade da alma. Este tem uma obra especifica sobre a morte intitulada "Fédon". Nesta obra, a morte é pensada como a libertação do pensamento, pensamento este que vivia preso em um corpo, e que depois da morte pode voltar ao plano das ideias. morte, na qual a alma sobrevive como uma tentativa de salvaguardar uma imortalidade para a vida humana. Contudo, o que interessa mais na concepção de Platão a respeito da morte é a afirmação da filosofia como conhecimento dedicado ao tema. Segundo Platão: "Receio, porém, que, quando uma pessoa se dedica à filosofia no sentido correto do termo, os demais ignoram que sua única ocupação consiste em preparar-se para morrer e estar morto!" (PLATÃO. 1983. 64a - 6-10) O debate da morte se coloca como importantíssimo dentro da filosofia, com isso certamente Sartre concorda, pois também trás o tema para dentro de sua ontologia fenomenológica.

Sabe-se, porém, que Sartre não concorda com a imortalidade da alma como defende Platão, que na visão sartriana, depois da morte há apenas a nadificação. Da mesma forma já pensava Epicuro sobre a morte. Em: "Carta a Meneceu” Epicuro diz:

Acostuma-te à idéia de que a morte para nós não é nada, visto que todo o bem e todo o mal residem nas sensações, e a morte é justamente a privação das sensações. A consciência clara de que a morte não significa nada para nós proporciona a fruição da vida efêmera, sem querer acrescentar-lhe tempo infinito e eliminando o desejo de imortalidade." (EPICURO, 2002, p. 27)

A morte para Epicuro não é um mal, pois com a morte já não somos nada, e não vamos pra lugar nenhum. Explica Reale:

"Como o homem é um "composto alma" em um "composto corpo", a morte não é senão a dissolução desses compostos, na qual os átomos se espraiam por toda parte, a consciência e a sensibilidade cessam totalmente e, assim, só restam do homem ruinas que se dispersam, isto é, nada.” (REALE. 2007. P, 270)

Epicuro diz que o sábio não teme a morte, pois com essa advém o nada, nada sentimos e nada somos, e não existe nenhum hades para ele, conforme sua teoria física descrita acima. Essa teoria da morte se aproxima muito a teoria sartriana ontológica e existencialista, pois o indivíduo também não é nada despois de sua morte e não vai pra nenhum lugar.

$\mathrm{Na}$ história da filosofia moderna o filósofo Schopenhauer também dedica um texto para o tema da morte chamado: "Metafísica da morte" no qual diz, regatando Sócrates: "A morte é propriamente o gênio inspirador, ou a musa da filosofia, pelo que Sócrates a definiu como preparação para a morte. Dificilmente se teria filosofado sem a morte" (SCHOPENHAUER. 2000. P, 59) Para esse filósofo a morte está ligada a morte do eu, do sujeito, mas não de sua essência íntima, a vontade de viver. Morrer é terminar a individualidade, a aparência e não a essência de nosso ser. Ele cita ainda o nirvana dos budistas como forma de negar a vontade de viver e consumar a morte tanto da aparência quanto da essência do ser, a existência se torna nada. "Ele renuncia voluntariamente à existência que conhecemos: o que lhe cabe em vez desta é aos nossos olhos é nada, porque nossa existência, referida àquela, nada é" (SCHOPENHAUER. 2000. P, 140). O budista ao atingir o nirvana e com a morte alcança a nadificação se libertando da cegueira da vontade.

Na história da filosofia contemporânea, destaca-se Sartre, filósofo existencialista que aborda a questão da morte em várias obras. Tanto numa linguagem filosófica e densa, quanto numa linguagem mais poética nas suas obras literárias. Para falar da morte em Sartre deve-se percorrer um caminho necessário dentro da obra principal, "O 
ser e o nada", o qual faz parte de um estudo ontológico sobre o ser e a consciência, mas não se limita a uma ontologia clássica, e sim uma ontologia fenomenológica, que foi herdada pelo pai da fenomenologia, Edmund Husserl. A influência de Husserl se vê clara quando diz Gerd Bornheim: "Se Sartre aceita a fenomenologia é com intenção de radicalizá-la ontologicamente. Seu fascínio pela fenomenologia não se restringe, portanto, a um interesse meramente metodológico" (BORNHEIM. 2011. P, 31). Tratase de ultrapassar o idealismo da consciência presente na fenomenologia de Husserl, para construir uma concepção ontológico-existencialista do humano e de sua morte.

\section{O ABSURDO DA MORTE}

O problema da absurdidade da morte não é a primeira definição sobre a morte que aparece na obra "O ser e o nada" de 1943, mas pretende-se demonstrar aqui sua anterioridade no tempo lógico das obras sartrianas. O próprio Sartre fala com vigor de tratar primeiro a morte por seu caráter de absurdo, segundo ele: "Antes de tudo, devemos sublinhar o caráter absurdo da morte" (SARTRE. 2015. p, 654). Essa é uma referência direta à obra literária "A naúsea" publicada em 1938, escrito que inaugura o existencialismo de Sartre, "antecipando em forma ficcional muitos dos argumentos filosóficos depois aprofundados no clássico O ser e o nada...” (LIUDVIK. 2019. Prefácio de A náusea).

Entre os temas presentes na obra literária está o absurdo da existência: “...A Náusea permite uma resposta mais imediata à nossa pergunta, por isso que todo o livro obedece a uma intuição básica que afirma a existência humana como gratuita, como um absurdo desprovido de qualquer sentido" (BORNHEIM. 2011. P, 20). A náusea é uma experiência ontológica, ou seja, vai muito além de uma experiência psicológica ou vivência emocional. É importante ressaltar que o título da obra originalmente dado por Sartre era Melancolia, contudo surge uma mudança:

Ao enviar o contrato para Sartre, Gaston Gallimard sugere que seja modificado o título. "Melancolia" era título que Sartre havia escolhido como referência ao quadro homônimo de Albrecht Dürer. Mas Gaston Gallimard não considera que "Melancolia" fosse um bom título e sugere um novo, que veio a consagrar a obra, A Náusea. (DIAZ. 2014. P, 22)

Acredita-se que tal mudança foi fundamental para o sucesso da obra, e mais, para expressar esta experiência ontológica de que fala o livro. Com a náusea: "Sartre instaura um procedimento semelhante ao da dúvida em Descartes" (BORNHEIM. 2011. $P, 19)$. Trata-se de se abrir ao interrogar com ingenuidade, ou seja, busca-se duvidar do mundo para uma compreensão mais profunda do humano e da morte. O ser só será desvelado por essa experiência negativa dada pela náusea, pois Sartre compreende o humano como negatividade. O que significa dizer que o ser do humano é negatividade? Se comparada a presença do em-si, que é plena, o para-si tem a negação em seu seio. Explica Sartre:

Contudo, nossos exemplos mostraram um Para-si que nega concretamente ser tal ou qual ser singular. Mas era porque descrevíamos a relação de conhecimento levando mais em conta, sobretudo, elucidar sua estrutura de negatividade. Nesse sentido, pelo próprio fato de ser desvelada por exemplos, esta negatividade já era secundária. A negatividade como transcendência originária, não se determina a partir de um isto, mas faz com que exista um isto. (SARTRE. 2015. P, 242)

Diante do mundo com sua plenitude esmagadora somos meros seres em 
negação, seres incompletos, e seres que tem no caminho a morte como destino. A morte é um absurdo porque o mundo que vivo me coloca em projeto, como ser em mudança, como ser sem completude. O absurdo da existência de um ser em-si em comparação com meu ser para-si faz resgatar a questão da morte como tema fundamental de minha angústia, de meu tédio, e de minha náusea perante a grandeza da existência do ser em-si e de minha liberdade de ser o que eu quiser, perante meu fundamento na negatividade de ser. Diz Sartre ainda sobre a negatividade do Para-si:

O Para-si, que se mantém frente ao ser como sua própria totalidade, sendo ele mesmo todo da negação, é negação do todo. Assim, a totalidade acabada, ou mundo, se revela como constitutiva do ser da totalidade inacabada pela qual o ser da totalidade surge ao ser. (SARTRE. 2015, p, 243)

O humano enquanto negatividade é totalidade inacabada, esse é o caráter negativo que se coloca na experiência da náusea, a experiência do absurdo da vida e da morte deve ser descritos como temas existenciais que movem o humano a refletir sua própria condição. Conforme explica Sartre: "É absurdo que tenhamos nascido, é absurdo morrermos; por outro lado, esta absurdidade se apresenta como alienação permanente de meu ser-possibilidade, que não é mais minha possibilidade, mas a do outro" (SARTRE. 2015. p, 670) A náusea mostra o absurdo da minha existência, porque a existência se coloca demais para o eu, esse demais significa as infinitas possibilidades de escolhas diante de minha liberdade.

Dizer que a castanheira aparece demais para mim, carregada de sua plenitude e finitude esmagadora, implica dizer minha existência é tão inacabada que me vejo angustiado pelo ser em-si, mas também reconheço com a náusea a minha existência livre para completar-se, essa liberdade parece demais para um ser que carrega a negação em seu ser. "Eis o mérito da náusea: a realidade perde sua razão de ser" (BORNHEIM. 2011.p, 21).

Contudo, para Sartre em A náusea, o ser humano também é demais. E aqui se chega no existencialismo e no humanismo tão defendidos pelo filósofo. $\mathrm{O}$ reconhecimento da existência da subjetividade como demais vem acompanhado nessa obra com adjetivos como, eu sou fraco, enlanguescido, obsceno, e movo mornos pensamentos. (BORNHEIM. 2011.p, 21) O que importa se o mundo é demais para o eu, se o próprio eu é demais para si mesmo? Se o eu não aguenta sua própria existência talvez seria o caso de encontrar-se com a morte, contudo Sartre nega o suicídio, isto é: mesmo o suicídio resulta injustificável"(BORNHEIM. 2011. P, 21)

A existência como demais, como sobrando, como totalidade plena diante de minha totalidade inacabada, resgata o tema da morte, contudo mesmo a morte é demais:

Sonhei vagamente em me suprimir, para aniquilar ao menos uma dessas existências supérfluas. Mas minha morte seria demais. Demais meu cadáver, meu sangue sobre esses seixos, entre essas plantas, no fundo desse jardim sorridente. [...] Eu era demais para a eternidade.

(BORNHEIM. 2011. P, 21)

A náusea faz compreender essa falta de sentido do mundo, da existência, da vida e da morte, ou seja, o absurdo de estar aqui e nem mesmo poder recorrer ao suicídio que é visto por Sartre como o absurdo dos absurdos: "O suicídio é uma absurdidade que faz minha vida soçobrar no absurdo" (SARTRE. 2015. p, 662). Sobre o suicídio diz ainda: "seria inútil recorrer ao suicídio para escapar a esta necessidade. O suicídio não pode ser considerado como um fim de vida do qual eu seria o próprio fundamento" 
(SARTRE. 2015. P, 661) Esta necessidade referida por Sartre é a necessidade de preencher o vazio de sentido da existência. Contudo, ele alerta: "Assim, a morte jamais é aquilo que dá à vida seu sentido: pelo contrário, é aquilo que, por princípio, suprime da vida toda significação" (SARTRE. 2015. P, 661) Não é através do suicídio ou da morte em geral que vou ser o fundamento de mim mesmo e de minha existência.

A obra A náusea apresenta ainda mais considerações acerca da absurdidade da existência. De acordo com Bornheim:

A palavra absurdidade nasce agora sob minha pena. [...] A absurdidade não era
uma ideia em minha cabeça, nem um sopro de voz, mas essa longa serpente morta
a meus pés, essa serpente de madeira. Serpente ou garra ou raiz ou presa de
abutre, pouco importa. E sem nada formular claramente, compreendi que havia
encontrado a chave da Existência, a chave de minhas Náuseas, de minha própria
vida. De fato, tudo o que consegui apreender em seguida se reduz a essa
absurdidade fundamental. (1938, p, 163-164. Apud. BORNHEIM. 2011. P, 21)

O absurdo é o mundo que se coloca a mim como um grande ser em sua nudez, logo o absurdo é absoluto, ser total. O mundo gera a minha náusea, e esta provém da existência: “...a existência requer um sentido impossível que apenas poderia ser alcançado no absoluto, mas o que há é absurdo...” (SILVA. Filosofia, literatura e dramaturgia. $\mathrm{P}$, 94). Assim, a náusea como sentimento negativo move o sujeito a pensar que nascer e morrer são um absurdo. No plano ontológico só existe aparências, fenômenos, logo, "...o absurdo conduz à ideia de uma radical contingência" (BORNHEIM. 2011. P, 22) Isto significa que a existência não é necessidade, mas que existir é estar aí simplesmente. Existir é estar aí nessa contingência que me coloca perante a morte. "A morte é simplesmente um fato puro ou facticidade derivada de minha contingência e de ser nada" (SILVA. 1997. P, 96).

Trata-se ainda de descrever um pouco do anti-herói Roquentin de "A náusea". Ele é um indivíduo normal, um historiador que se instala numa cidade pequena para pesquisar a biografia de um político menor, o marquês de Rollebon. A princípio ele crê que a existência humana, a sociedade e a história têm sentido, mas aos poucos a inexorabilidade da náusea penetra seu ser e todas as dimensões do real. (BORNHEIM. 2011. P, 20). Segundo Caio Liudvik:

Pouco a pouco, porém, a relação de Roquentin com sua pesquisa, com a cidade e com a sua vida vai sendo minada por inquietações materializadas literalmente em crises de 'náusea', mal-estar de alguém cujo solo firme parece se transmutar num mar revolto e enjoativo em que a falsa imagem domesticada do real afunda. Estávamos, vale lembrar, às vésperas da Segunda Guerra Mundial. (LIUDVIK, 2019. prefácio de "A náusea")

Como resultado dessa obra tem-se a instauração de um novo humanismo (BORNHEIM. 2011, p, 22). O quadro negativo que se coloca na Náusea, deve ser medido pela contingência que é gratuidade perfeita, e por aí está a conclusão que:

A raiz da náusea reside nessa gratuidade, e a coragem desse anti-herói que é Roquentin consiste em viver a náusea até atingir o absoluto radical que a torna possível. O sentido final da novela se condensa na frase que diz: 'Todo existente nasce sem razão, prolonga-se por fraqueza e morre por acaso. (BORNHEIMER. 2011. P, 22)

O existencialismo humanista de Sartre em "A náusea" não acaba num negativismo absoluto, mas aponta para uma transcendência, qual seja, a ruptura com o absurdo da náusea e a possibilidade que ali se instaura, que é a compreensão do humano 
como falível, mas também como único autor de sua existência, como aquele que possui a liberdade para mudar sua própria situação, sem é claro cair na má-fé. É preciso pensar a náusea e o absurdo da morte como momentos que permitem vislumbrar algo positivo do existir, a possibilidade de escolha diante da liberdade definidora do ser do para-si. Segundo Silva:

Roquentin está livre e sozinho; a liberdade, efeito imediato da experiência da Náusea, é a presença a si. Por isso, Roquentin está atrelado a esse átimo instável do tempo e é constituído por ele; trata-se de uma espécie de sonho, no qual o passado, tal qual uma erosão, tenta alcançar o presente e também torná-lo nada. (SILVA. 2006. P, 94)

Fica claro que o absurdo da morte, morte esta que não faz parte da estrutura ontológica do ser-para-si, é um aspecto negativo da náusea, mas que ao mesmo tempo aponta para um transcender essa angústia, e um refugiar-se no humano com sua liberdade instaurada pela consciência. Cabe agora analisar como a liberdade influência na nossa visão da morte. A Facticidade da liberdade é o fato que a liberdade existe que ela se exerce no mundo dado sem que haja escolha quanto a isso. Segundo Philippe Cabestan:

É, pois, detalhando os diferentes aspectos desse dado que nos podemos esperar atingir mais concretamente os limites que a liberdade encontra surgindo no mundo. O ser e o nada encaram esse dado sob cinco aspectos diferentes: meu lugar, meu passado, meus arredores, meu próximo e minha morte. (CABESTAN. 2005. P, 33)

É desta divisão da facticidade da liberdade que surge o problema da morte em $O$ ser e o nada. Segundo Sartre: "O conceito técnico e filosófico de liberdade, o único que consideramos aqui, significa somente: autonomia de escolha" (SARTRE. 2015. P, 595). Dentre os exemplos citados da liberdade em situação está o acontecimento limite, a morte, esta explica Sartre se coloca como o limite da vida, mas ainda fazendo parte da existência. Não quer dizer que a morte seja uma escolha nossa, mas está no limite das possibilidades da liberdade. Ele diz: “...o homem já nada mais pode encontrar senão o humano; já não há mais outro lado da vida, e a morte é um fenômeno humano, fenômeno último da vida, mas ainda vida." (SARTRE. 2015. P, 652) A morte como busca de sentido da existência, se humaniza e se interioriza, a morte se converte agora no sentido ou na busca de sentido da vida. Não se trata da morte no todo, mas da minha morte individual, a morte como fenômeno da minha vida pessoal.

Apontamento importante é dizer que a morte não é minha possibilidade, ora, dentro do esquema da liberdade, a morte é uma situação limite, como um avesso inelutável de minhas possibilidades. A morte como explica Sartre é interiorizada como 'última', ou seja, como possibilidade fim de minhas possibilidades. A morte não é minha possibilidade, porque ela é esse avesso de a assumir como já não havendo mais possibilidades para um eu. Sartre diz: “...a morte não me atinge.”(SARTRE. 2015. P, 671), porque ela é apenas a afirmação de ausência de possibilidades, ausência de projeto, ela é afirmação de meu nada. Isto implica em dizer com ele que "Não sou 'livre para morrer', mas sou um livre mortal" (SARTRE. 2015. P, 671). A minha liberdade é minha vida, a minha morte já não é mais vida, por isso ela é ausência de liberdade.

\section{A MORTE COMO NADIFICAÇão}

A morte como limite deve ser considerada contendo uma dupla face, ou seja, ela 
pode ser vista como aderente ao nada, ou como aglutinado da série por ela terminada. $\mathrm{O}$ primeiro modo filosófico de considerar a morte é através da nadificação, ou seja, a morte é pensada como: “...uma porta aberta ao nada de realidade humana, sendo esse nada, além disso, a cessação absoluta de ser ou a existência em uma forma não humana." (SARTRE. 2015. P, 652). A história da filosofia desde Epicuro pensa o nada como resposta à morte, o fim da existência é a nadificação, não haveria uma imortalidade do humano, nem de sua alma.

Para Sartre tal concepção sobre a morte está inteiramente ligada ao conceito de para-si e suas características ontológicas. A morte não faz parte da estrutura do para-si, como diz Sartre:

Com efeito, na medida em que é nadificação sempre possível de meus possíveis, a morte está fora de minhas possibilidades, e, por conseguinte, eu não poderia espera-la, ou seja, arremessar-se rumo a ela como se fosse rumo a uma de minhas possibilidades. Portanto, a morte não poderia pertencer à estrutura ontológica do Para-si. (SARTRE. 2015. P, 667-668)

No capítulo sobre a "Concepção fenomenológica do nada", Sartre fala da importância da novidade do conceito de nada para Heidegger em relação à Hegel e resume numa frase muito significativa:

Contudo, ainda que estabelecendo as possibilidades de captação concreta do Nada, Heidegger não cai no erro de Hegel e não conserva no Não ser um ser, mesmo abstrato: o Nada não é, o nada se nadifica. Está sustentado e condicionado pela transcendência. (SARTRE. 2015. P, 59. Grifo nosso)

Como se deve entender essa nadificação do para-si? Pode-se com Cabestan: "Nos temos visto que o para-si não é fundamento nem de seu ser nem de seu nada, e que seu surgimento resulta de uma nadificação primeira." (CABESTAN. 2005, p, 33) Conforme explica Sartre em "origem do nada": "O Ser pelo qual o Nada vem ao mundo deve nadificar o Nada em seu ser..." (SARTRE. 2015. P, 65) Assim, a nadificação é uma característica ontológica do ser requerido, do para-si. Este como nadificação original é relação ao em-si, relação essa que faz surgir a situação, que é a facticidade e contingencia absoluta. Sobre essa relação explica Cléa Gois e Silva:

Neste momento, o tema da intencionalidade adquire a dimensão ontológica. $\mathrm{O}$ Para-si é relação ao em-si, como já dissemos: ele se confunde com seu próprio nada, e permanece separado do em-si, por nada. (SILVA. 1997. P, 30)

Segundo Sartre: “O nada não pode se nadificar a não ser sobre um fundo de ser: se um nada pode existir, não é antes ou depois do ser, nem de modo geral, fora do ser, mas no bojo do ser, em seu coração, como um verme". (SARTRE. 2015. P, 64) O nada está no para-si como um verme, como algo que o constitui, mas não necessariamente o fundamenta. Pergunta-se se esse nada já presente no seio do humano não o coloca já num estado de morte, ou pelo menos o aproxima da morte como ser que ao deixar de ser projeto, passa a ser nada. A morte e a negação estão no coração do humano, por isso o existencialismo enfatiza a morte como exemplo de situação. Sartre explica que:

Minha posição no meio do mundo, definida pela relação de utensilidade ou de adversidade entre as realidades que me circundam e minha própria facticidade, ou seja, a descoberta dos perigos que corro no mundo, dos obstáculos que nele posso encontrar, das ajudas que podem me ser oferecidas, à luz de uma nadificação radical de mim mesmo e de uma negação radical e interna do Em-si, operada do ponto de vista de um fim livremente posicionado - eis o que denomino situação. (SARTRE. 2015. p, 672) 
A morte faz parte da nadificação do ser do para-si em existência, ou seja, em situação, mas também faz parte do caráter inumano, isto é, do pós-existência do para-si, que com a morte passa ser o nada absoluto. Esta caraterística faz da morte um tema importante no existencialismo ateu de Sartre, o qual se tem como objetivo as próximas considerações.

\section{O EXISTENCIALISMO E A MORTE}

O existencialismo ateu sartriano faz pensar na morte como intrínseco ao ser humano, logo este limite de acontecimento dado na morte, esta cessação das possibilidades e da liberdade do ser como totalidade em processo de ser, coloca o humano cara a cara com seu fim, como sua morte. A náusea como princípio ontológico da vida também carrega a morte nas costas como Atlas carrega o mundo. Uma filosofia verdadeiramente existencialista tem que se colocar o tema da morte para pensar a facticidade do sujeito. Não apenas no sentido de defini-la, mas no sentido de reconhecer a sua presença no seio do próprio ser humano.

A morte é um acontecimento inesperado e imprevisto, pois ela pode chegar a qualquer tempo, mesmo que eu não esteja nunca pensando nela. Como diz Sartre: “...o próprio da morte é que ela sempre pode surpreender antes do tempo aqueles que a esperam para tal ou qual data" (SARTRE. 2015. P, 657). Acredita-se ser o existencialismo ateu um tipo de filosofia que nos impõe uma preocupação com a morte, pois com o fim dos determinismos morais, o sujeito é responsável pelo seu próprio projeto de existência. Pensar a morte nessa perspectiva é transcender o medo irracional e afirmar a finitude como característica essencial do ser-para-si.

A visão existencial da vida ajuda a perder o medo da morte, e nos coloca diante do nada, mas principalmente faz o ser humano assumir que é ele o único responsável por fazer a sua vida, por trilhar o seu caminho. Uma das grandes verdades que o humano tem que assumir em sua facticidade é que: "O homem nada mais é do que aquilo que faz de si mesmo: é esse o primeiro princípio do existencialismo". (SARTRE. 1987. P, 6) Ao concordar com a tarefa humana de fazer-se a si mesmo, o sujeito deve pensar a morte como limite, como último ato de existência. Contudo, a morte não dá a vida o seu significado, na verdade ela retira todos os significados da vida.

Ao compreender a tarefa infinita de fazer-se diante das várias possibilidades dadas pela liberdade, a subjetividade pautada no existencialismo ateu de Sartre pensa que a morte: “...não é mais concebida como tendo qualquer significação especial em termos de nos individuar”. (REYNOLDS. 2014. P, 127) Eu sou um ser jogado no mundo, a minha existência não tem um sentido especial, e porque teria um sentido especial a minha morte?

O existencialismo de Sartre afirma que se Deus não existe há pelo menos um ser no qual a existência precede a essência: "Lançado na existência sem o meu consentimento, eu devo assumir essa existência, fazendo-me ser o que eu quero, e sem poder contar com mais ninguém senão comigo". (SILVA. 1997. P, 83) O homem só se define porque a principio ele não é nada, o homem não tem uma natureza humana, pois não existe um Deus para concebê-la. Para esta concepção a dignidade do homem é maior do que das coisas do mundo, porque o humano é um projeto, ou seja, aquilo que se projeto no futuro e tem consciência de estar se projetando no futuro. (SARTRE. 1987.p, 6)

A moral existencialista é a moral do engajamento, a única esperança do humano está em suas mãos. O engajamento significa tomar sua vida para si e fazer dela algo, 
além disso, significa fazer escolhas sempre, mas com responsabilidade. Sartre cita o exemplo da revolução russa, segundo ele não posso afirmar que tal situação irá conduzir ao triunfo do proletariado. (SARTRE. 1987. P, 13) e continua:

Não posso ter certeza que meus companheiros de luta retomarão o meu trabalho após minha morte para o conduzir à máxima perfeição, visto que esses homens são livres e decidirão livremente, amanhã, sobre o que será o homem; amanhã, após a minha morte, alguns homens podem decidir instaurar o fascismo... (SARTRE. 1987.p, 13)

Esse exemplo é para mostrar que a morte, a minha morte individualizada, é o ponto culminante de minhas ações, de minhas possibilidades, e toda subjetividade é livre para escolher o que fazer com a minha morte. $O$ outro não vê minha morte como a morte em geral, mas a minha morte pesa como um limite aos outros, e esses podem resolver ignorá-la ou não. Assim, entra a memória do que fiz como condutora de um processo de reconhecer o limite do humano através da morte.

Nesse mesmo sentido, Sartre reconhece que a ação é a premissa existencialista fundamental, pois é como o engajamento na ação que a situação histórica pode mudar. A morte só se torna rememorável pelas ações que a pessoa fez durante a vida. Diz:

As situações históricas variam: o homem pode nascer escravo numa sociedade pagã ou senhor feudal ou proletário. O que não muda é o fato de que, para ele, $e ́$ sempre necessário estar no mundo, trabalhar, conviver com os outros e ser mortal. (SARTRE. 1987. P, 16. Grifo nosso)

A morte como fato da vida está sempre batendo a porta da existência, por isso não posso me esquecer que ser mortal faz parte dessa vida, que pode não ter um sentido, mas que tem a liberdade como guia, ou seja, quem faz o sentido da sua vida e a própria subjetividade engajada. Uma coisa clara no existencialismo é que a minha liberdade depende da liberdade dos outros, e a liberdade dos outros depende da minha. Não assumir a mortalidade é um ato de má-fé, não assumir sua responsabilidade diante de seus atos, é cair num determinismo da moral, o qual, só vai mascarar a finitude e a morte. Não se pode agir como se a morte não existisse. Fingir que a morte não existe é criar uma mentira para dissimular a total liberdade do engajamento.

\section{A MORTE E A MÁ-FE}

Como foi dito, na visão existencialista a morte não pode ser mascarada pela máfé. Mas qual a verdadeira relação da má-fe com a minha morte? Determinar a mentira que cada indivíduo inventa para si mesmo, isso é bem difícil, contudo, na questão da morte, parece que a má-fé reina plena e absoluta. Além, da tentativa do humano de sempre se esconder da morte certa, há também o fato de achar que a morte está bem longe de cada um de nós. Segundo Sartre: “...somente por cegueira ou má-fé podemos esperar uma morte por velhice” (SARTRE. 2015.p, 658).

A morte pode vir antes que se possa cumprir as tarefas colocadas por cada um diante da existência. O que Sartre chama de fato de má-fé? "Aceitemos que a má-fé seja mentir pra si mesmo, desde que imediatamente se faça distinção entre mentir a si mesmo e simplesmente mentir. Admitimos que a mentira é uma atitude negativa." (SARTRE. 2015. P, 93) o ideal do mentiroso é uma consciência cínica, que afirma em si a verdade, mas que recaiu numa dupla negação. A disposição do mentiroso é positiva, pois ele pretende enganar e não dissimular essa intenção. Para quem pratica a má-fe, “...trata-se de mascarar uma verdade desagradável ou apresentar como verdade um erro 
agradável. (SARTRE. 2015. P, 94)

O indivíduo que vive na má-fé sabe muito bem da verdade para poder escondê-la de si mesmo com maior cuidado. Diz Sartre:

Pode-se viver na má-fé, o que não significa que não se tenham bruscos despertares de cinismo e boa-fé, mas sim implica um estilo de vida constante e particular. Nossa perplexidade, portanto, parece ser a maior possível, já que não podemos nem rechaçar nem compreender a má-fé. (SARTRE. 2015. P, 95)

A má-fé com relação à morte é uma verdade que o indivíduo esconde de si mesmo, e faz parecer aos outros que não se importa com a chegada da sua morte, e mesmo torna sua ação cínica ao não pensar nas consequências morais que envolvem a vida do outro.

\section{A MORTE NA VISÃo dO SER-PARA-OUTRO}

Se a morte é sempre minha morte então porque falar da visão do ser-para-outro sobre minha morte? A morte é um acontecimento que só concerne ao para-si, contudo são os outros que fazem o ritual da minha morte ser de um jeito ou de outro, são os outros que me julgam que me mantém na memória ou não. Em resumo diz Sartre: "Estar morto é ser presa dos vivos" (SARTRE. 2015. p, 666) o que ele quer dizer com isso é que mesmo na morte o inferno são os outros, ou seja, vai depender do outro o julgamento da minha própria existência. Apesar da morte seu minha última possibilidade, ela é minha possibilidade irrefletida, logo é fácil dizer: "mas na morte somos completamente entregues aos caprichos do outro; ele permanece livre para nos caracterizar como quiser, mas nós não teremos mais a possibilidade de replicar." (REYNOLDS. 2019. P, 129.) Nada posso dizer sobre minha morte, quem diz é sempre o outro, e ele pode dizer o que quiser.

Sartre coloca um caráter bem negativo acerca da perspectiva do outro sobre a morte do para-si. Parece ser uma perspectiva bem pessimista, pois quando ocorre a morte de alguém esse alguém, na maioria das vezes e pelo senso comum, é sempre visto como uma pessoa boa, integra e honesta. Esse caráter de negatividade se coaduna com a necessidade intrínseca do outro em meu ser, ou seja, uma necessidade ontológica. $\mathrm{O}$ humano é "um ser quem implica o ser do outro em seu ser" (BORNHEIM, apud de Sartre, "O ser e o nada". 2011. P, 83) Para Bornheim, o para-si descobre a realidade do outro, um exemplo é a vergonha. Vergonha é reconhecimento, pois reconheço que sou como o outro me vê.

$\mathrm{O}$ outro sempre me aparece como objeto, como objeto que devo conhecer, nessa perspectiva a intersubjetividade torna-se mais complexa. Segundo Sartre somente Heidegger supera a visão de conhecimento da intersubjetividade, segundo Sartre falta a Heidegger a explicitação do fundamento da relação intersubjetiva. (BORNHEIM. 2011. $\mathrm{P}, 83$ ). Para Sartre, no seu existencialismo o outro é apreendido de forma direta, como no cogito cartesiano. O solipcismo toma conta e coloca a questão no plano da probabilidade. O para-si e fundamento tanto da negatividade quanto da relação, logo: “...Sartre se empenha em mostrar que entre eu e o outro há uma 'ligação fundamental', e que nela se manifesta uma modalidade de presença do outro irredutível ao conhecimento que tenho de um objeto.” (BORNHEIM. 2011. P, 86) Não dá para pensar o para-si, o sujeito, sem pensar no outro para-si que o observa e o rodeia.

Enquanto há vida a relação entre eu e o outro existe de uma forma um pouco velada, uma relação entre um para-si e o ser-para-outro, perpassa a vergonha, o olhar do 
outro me julgando, entre outras coisas, há aqui uma ligação, mas na morte da subjetividade essa relação se torna mais negativa. Como diz Sartre:

Mas, agora que sua vida está morta, somente a memória do outro pode impedir que ela atrofie até sua plenitude de Em-si, rompendo todas as suas amarras com o presente. A caraterística de uma vida morta é ser uma vida da qual o outro se fez guardião. (SARTRE. 2015. p, 663)

Esperar ser lembrado é o que resta da relação entre um eu e o outro. Enfim, é uma triste verdade não ser nem lembrado na consciência dos outros eus. Sartre afirma: "Ser esquecido é ser objeto de uma atitude do outro e de uma decisão implícita do outro". (SARTRE. 2015. p, 664). Por isso Sartre diz que somos presas do outro, o outro tem o poder de me manter vivo em sua memória ou não. Daí o pessimismo de Sartre em relação ao outro e sua conduta diante da morte do eu. "O meu acesso essencial à intersubjetividade dá-se pela negação; nego o outro como aquele que me nega, e pela negação do outro me reconheço como para-si" (BORNHEIM. 2011. P, 93) A negação é a explicação do pessimismo em relação ao outro.

A minha morte não pertence a minha estrutura ontológica, pois a minha morte depende do outro, de um outro para-si que possa sofrê-la ou esquecê-la. Diz Sartre: "É por causa do outro que minha morte constitui minha queda fora do mundo, a titulo de subjetividade, em vez de ser o aniquilamento da consciência e do mundo" (SARTRE. 2015. P, 668). A morte faz parte da facticidade do mundo, ela é contingência, enquanto tal ela é memorada pelo outro, e esta memória pode ser boa ou ruim ao bel prazer do outro ser que memora. Por mais que o para-si controle seu projeto de existência na presença da morte ele está, em último caso, na mão do outro.

\section{Conclusão}

A morte na história da filosofia é discutida em vários períodos diferentes, desde sua concepção acerca da imortalidade da alma, até enquanto nada epicurista. Para Sartre a morte é um absurdo que se torna maior ainda porque o outro é responsável pelo meu desaparecimento no mundo, ou seja, pela minha queda. A morte é também pensada como a última das possibilidades do meu para-si. Apesar de a morte ser um absurdo, o suicídio não é solução coerente para o existencialismo. Resta viver longe da má-fé e ter a certeza que não haverá nenhum outro mundo para ir, além disso, deve-se pensar que a morte só faz sentido mesmo na presença do outro. Minha morte é sentida na memória e na fala do outro sobre minha existência.

\section{REFERÊNCIAS}

BORNHEIM, Gerd. Sartre. Metafisica e existencialismo. São Paulo: Perspectiva, 2011.

CABESTAN, Philippe. Une liberté infinie? In Sartre: désir et liberte. Coordonné par Renaud Barbaras. Paris: Presses Universitaires de France, 2005.

DIAZ, Luís Anderson Moraes. Liberdade, humanismo e escrita em Jean-Paul Sartre. Dissertação (Dissertação em Filosofia). Universidade São Judas Tadeu. São Paulo: 2014.

EPICURO. Carta sobre a felicidade. Trad. Álvaro Lorencini e Enzo Del Carratore. São Paulo: UNESP, 2002.

PLATÂO. Fédon. In coleção Os pensadores. São Paulo: Abril Cultural, 1983.

REYNOLDS, Jack. Existencialismo. Petrópolis, RJ: Vozes. 2006.

SCHOPENHAUER. Metafísica do amor/ Metafísica da morte. São Paulo: Martins Fontes, 2000.

SARTRE. Jean-Paul. O existencialismo é um humanismo. In coleção Os pensadores. São Paulo: 
Nova Cultural, 1987.

SARTRE. Jean-Paul. O ser e o nada - ensaio de ontologia fenomenológica. Petrópolis, RJ: Vozes, 2015.

SARTRE. Jean-Paul. A náusea. Rio de Janeiro: Nova Fronteira, 2019.

SILVA, Luciano Donizetti. Filosofia, Literatura e Dramaturgia: liberdade e situação em Sartre. In

110 revista: Doispontos, Curitiba, São Carlos, vol. 3, n. 2, p.83-103, outubro, 2006. Ed. Da UEL, 1997. 